\title{
PEDAGOGIAS DA VOZ NA ARTE PALHACESCA: um estudo sobre a iniciação com oito artistas brasileiros
}

\section{Voice pedagogies in the clownesque art: \\ a study on the initiation with eight brazilian artists}

Gilberto Icle

Universidade Federal do Rio Grande do Sul - UFRGS

Guilherme Bruno de Lima

Universidade de Brasília - UnB

Resumo: Este trabalho tece alguns apontamentos acerca da vocalidade poética no território da arte do/a palhaço/a. Objetiva-se analisar como a voz poética permeia os processos de iniciação à arte palhacesca com oito artistas brasileiros. Trata-se de uma pesquisa empírica a partir de entrevistas semiestruturadas em diálogo com autores como Paul Zumthor (no tocante à vocalidade), Luís Otávio Burnier e Ana Elvira Wuo (no tocante a arte do/a palhaço/a), dentre outros. Apresenta-se a vocalidade dos palhaços e das palhaças como modos de pensar a voz na sua dimensão poética e na sua potência.

Palavras-chave: Voz; Palhaço; Circo; Teatro.

Abstract: This paper draws some key points concerning the poetic vocality within the territory of the clown's art. It is aimed to analyze how the poetic voice permeates the initiation processes to the clownesque art with eight Brazilian artists. It is an empirical research based on eight semi-structured interviews, in dialogue with authors like Paul Zumthor (concerning vocality), Luís Otávio Burnier and Ana Elvira Wuo (concerning the clown's art), among others. The vocality of male and female clowns is presented as ways of thinking the voice in its poetic dimension and in its potency.

Keywords: Voice; Clown; Circus; Theater. 


\section{Gilberto Icle \\ Guilherme Bruno de Lima}

O presente texto traz alguns apontamentos para pensarmos sobre a voz poética no campo da palhaçaria. Para essa operação, iremos nos focar no processo de iniciação de oito palhaços e palhaças brasileiros, tramando ideias de Paul Zumthor e de artistaspesquisadores da arte palhacesca.

Este trabalho é fruto de uma pesquisa que busca compreender como a voz permeia a iniciação palhacesca apoiando-nos numa abordagem empírica subsidiada por entrevistas semiestruturadas com um grupo de oito artistas brasileiros, a saber: Esio Magalhães (palhaço Zabobrim), Paula Sallas (palhaça Xicaxaxim), Denis Camargo (palhaço Chupadinho), Zé Regino (palhaço Zambelê), Manuela Castelo Branco (palhaça Matusquella), José de Abreu Brasil (palhaço Pimenta), Jussier Lira (palhaço Colorau) e Samia Bittencourt (palhaça Nada).

As entrevistas nos forneceram alguns apontamentos sobre o tema. As falas dos/das iniciados/das revelaram, por meio de suas experiências, possíveis usos da voz poética no território do/a palhaço/a, fazendo-nos pensar sobre o que denominamos de marcos da vocalidade palhacesca. Situamos esses marcos no processo de iniciação, no qual prevalece uma peculiar zona de aprendizagem e de experiência. Essa zona possibilita a quebra da seriedade e o primeiro contato com nossos aspectos ridículos pelo viés da arte da palhaçaria, seus princípios, práticas e saberes.

Assim, nossa abordagem agrega-se ao campo das pesquisas em comicidade e palhaçaria para pensar a voz poética no ato de iniciação em três marcos, ou seja, três dimensões. A primeira problematiza o silêncio como um elemento basilar das iniciações de nossos sujeitos. Seria o silêncio algo fixo, amordaçado, que repousa sobre uma imposição do não-falar? Ou seria o silêncio uma possibilidade de aprendizagem do "corpar" da comicidade palhacesca? Wuo diz que o "corpar" é um princípio móvel e flexível, no qual "[...] o desfazer, desformar o corpo em situação de iniciação, cria estruturas cognitivas, sensório motoras, perceptivas inusitadas" (2013, p.113). A segunda, busca pensar a voz poética em sua materialidade, em sua capacidade de romper com a própria linguagem no seu aspecto material, pela sua própria presença, sua força. E, por fim, a terceira trata da voz como elemento singular dos próprios sujeitos que, para além da iniciação propriamente dita, operou na criação e/ou radicalização de poéticas, modos de palhaçar nos quais a presença da voz tornouse singular.

\section{Voz e iniciação}

A iniciação à arte de palhaços e palhaças é um momento bastante singular para cada um, cada uma. Trata-se de um processo único, multifacetado e que pode ocorrer sob contextos diversos como, por exemplo, oficinas e cursos ou, no próprio picadeiro sem a perspectiva formal que uma oficina ou curso propicia para tal iniciação.

Nesta pesquisa, do total de oito palhaços e palhaças entrevistadas, cinco se iniciaram em situações pedagógicas que se deram pela condução de um mestre (Esio Magalhães, Paula Sallas, Denis Camargo, Zé Regino, Manuela Castelo Branco), num recorte pedagógico específico de saberes e práticas da arte palhacesca. Em suas iniciações, esses saberes e práticas visavam explorar o corpo no intuito de evidenciar o ridículo de cada

Revista Moringa - Artes do Espetáculo, João Pessoa, UFPB, v. 9 n. 2, jul/dez 2018, p. 89 a 110

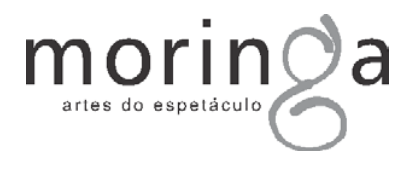


sujeito na busca pelas primeiras pistas sobre o "corpar" da comicidade no território do palhaço, da palhaça.

Por outro lado, no segundo grupo (José de Abreu, Jussier Lira e Sâmia Bittencourt), esse modelo de situação pedagógica, com a presença de um mestre está ausente. Em seu lugar toma forma uma situação pedagógica, digamos "alternativa" (ainda que tradicional ao circo), pois trata-se do "jogar-se" no espaço da cena, na improvisação. No picadeiro do circo, por exemplo, é muito comum que um artista se inicie quando o palhaço ou a palhaça principal do circo se ausenta, ainda que temporariamente. Essa situação pode ser considerada pedagógica na medida em que ela "ensina" a ser palhaço e o público se converte ele mesmo em mestre/mestra da iniciação. Neste grupo, tanto José de Abreu como Jussier, iniciaram-se no picadeiro. Sâmia, por sua vez, iniciou-se no próprio espaço da cena, mas sem a presença de um mestre, razão pela qual não se encontra em nosso primeiro grupo. Em todo caso, o corpo e a exposição ao ridículo, são o primeiro palco de todas as experiências.

Sob este ponto de vista - da iniciação no contexto formal ou informal -, esses são os dois grupos da pesquisa. Porém, como veremos mais adiante, do ponto de vista da experiência vocal durante a iniciação, pode-se constituir outra formação: Denis, Paula, Zé Regino, Sâmia e Manuela, num primeiro grupo e (sem uso da voz) por outro lado, Ésio, Jussier e José de Abreu, num segundo grupo (que, independente do território em que foi iniciado, usou a voz).
Aparentemente, a iniciação pode reverberar, ao menos a curto prazo, no modo de constituição de cada palhaço e palhaça. Isso porque, as "marcas" dessa primeira vivência são potências de afetar que apontam para o desenrolar de fluxos identitários do sujeito ridículo em sua descoberta no modo de ser palhaço/a, ou seja, a iniciação é propulsora dos primeiros aspectos ético-estéticos do sujeito em território palhacesco, o que, de certa maneira, poderá "direcionar" (mesmo que não de forma definitiva) sua silhueta como palhaço ou palhaça.

Para a pesquisa aqui apresentada, interessanos pensar como a abordagem e a presença da voz em perspectiva poética permeia esse processo de iniciação, no espectro do primeiro encontro com o universo palhacesco. Nas propostas de iniciação relatadas pelos/as entrevistados/as que vocalidades são afeitas a este universo? Como essas vocalidades podem desestabilizar os clichês e os estereótipos vocais de tais sujeitos no contexto da iniciação? Como foram iniciados esses palhaços e palhaças?

A palhaça e pesquisadora Ana Elvira Wuo, argumenta que:

[...] o ritual de iniciação é um processo que propõe um desprendimento das ações cotidianas do corpo do iniciante por meio de exercícios (físicos, lúdicos e imagéticos) e de preparação do corpo pessoal, encaminhando-o para uma soltura de formas, de gestos habituais, prontificando-o para receber e ser recebido por esse outro, que não sabemos quem é, mas que desejamos que nos encante para que se crie o clown. (WUO, 2016, p. 154) 
No ritual de iniciação, como aponta Wuo (2016), esse desprendimento provoca a construção de um universo extracotidiano, convidando, na prática, o corpo a enveredar por territórios que extrapolam 0 comportamento cotidiano e convencional. A autora vem se dedicando ao tema da iniciação no intuito de compreender os procedimentos que levam a exploração da qualidade cômica do corpo, observando a perspectiva autoral do mestre como interlocutor na experiência da iniciação (no caso, ela própria como mestra ao iniciar palhaços/as).

Todavia, ela circunscreve sua pesquisa tendo a iniciação como um ritual que para ser realizado, pressupõe a condução de um iniciador, ao mesmo tempo, em diálogo com Burnier, ressalta que "[...] nas famílias circenses, essa iniciação acontecia diretamente no picadeiro e a situação de constrangimento era enfrentada a cada dia de apresentação no picadeiro de circo" (WUO, 2016, p. 151). Burnier, por sua vez, argumenta que "[...] o trabalho de criação de um clown é extremamente doloroso, pois confronta o artista consigo mesmo, colocando à mostra os recantos escondidos de sua pessoa; vem daí seu caráter profundamente humano" (2009, p. 89). É, portanto, um processo eminentemente poiético e, ao mesmo tempo, misterioso.

Para podermos incluir na iniciação os palhaços e palhaças iniciados no picadeiro, pensamo-la como elemento por intermédio do qual o primeiro encontro com a arte palhacesca transborda (ou mesmo suprime) a questão ritual conduzida por um mestre ou mestra. É nesse sentido que o "jogar-se" na cena é também incorporado aqui a noção de iniciação para além das abordagens pedagógicas formais.

Para pensar o processo de iniciação, tendo a voz como ponto central de nossa reflexão, vamos recorrer ao conceito de vocalidade; e o faremos a partir do estudioso da voz poética, o medievalista suíço Paul Zumthor. Ele oferece uma perspectiva para pensarmos nos usos da voz pelos diferentes contextos poéticos, aduzindo a maneira por intermédio da qual pensa a voz no seu anelo irredutível com o conceito de vocalidade. Ele afirma que:

[...] é por isso que à palavra oralidade
prefiro vocalidade. Vocalidade é a
historicidade de uma voz: seu uso.
Uma longa tradição de pensamento, é
verdade, considera e valoriza a voz
como portadora da linguagem, já que
na voz e pela voz se articulam as
sonoridades significantes. Não
obstante, o que deve nos chamar a
atenção é a importante função da voz,
da qual a palavra constitui a
manifestação mais evidente, mas não
a única e nem a mais vital: em suma, o
exercício de seu poder fisiológico, sua
capacidade de produzir a fonia e de
organizar a substância. (ZUMTHOR,
1993, p. 21)

Com efeito, chama a atenção que o autor sublinha que a voz é algo concreto, devido a suas características materiais e que, a essas características, liga-se um valor simbólico de determinado grupo. Os parâmetros dessas características são: silêncio, ruído, intensidade, frequência, timbre, ritmo, contorno, direcionalidade, reverberação, entre outros, conforme nos lembra Lignelli (2014). Zumthor também nos diz que "[...] a voz é uma coisa: 
descrevem-se suas qualidades materiais, 0 tom o timbre, o alcance, a altura, o registro [...]" (1997, p. 11). É a essa materialidade de determinado grupo no elo com seu valor simbólico, que Zumthor (1993) se interessa para pensar o fenômeno da voz humana, em seus aspectos físicos, psíquicos e socioculturais. Por isso se debruça desde a voz dos Inuit canadenses aos griôs, dos trovadores aos artistas do medievo, dos repentistas do nordeste brasileiro aos jograis, dentre outros grupos e culturas que o pesquisador teve contato.

Imersos no que pensa Zumthor sobre a vocalidade, vamos nos debruçar então em diferentes elementos da iniciação de palhaços e palhaças, que emergiram de nossas entrevistas com eles, para compreender como esses elementos se articulam entre si e nos possibilitam entender o papel da voz na iniciação palhacesca.

Neste artigo, consideraremos vocalidade como conceito-chave de nosso trabalho, na medida em que, na perspectiva zumthoriana, ele imbrica voz e performance, cuja relação é vital para pensarmos nos liames poéticos da voz. Por outro lado, mesmo Zumthor (1997), ao se perguntar acerca da especificidade da poesia oral no início de sua pesquisa (em "Introdução à Poesia Oral"), considera a noção de performance e os efeitos de presença, de corpo, nessa relação, a partir do termo oralidade. Entretanto, ele ainda mantinha uma dicotomia com a escrita, compreendendo a dimensão do oral como território demarcado (somente) pela língua.
Com efeito, ao criar o conceito de vocalidade, ele busca fissurar essa dicotomia, verticalizando sua pesquisa sobre os usos poéticos da voz: seus elementos subjetivos e materiais, seu poder, sua capacidade de dissolver a própria linguagem, sua potência nômade, sua força.

Assim, para o contexto da iniciação, a oralidade configura-se como tessitura presente na memória e na transmissão de saberes palhacescos (para além da tradição circense), porquanto a vocalidade, em alinhavo com a performance, é energia propriamente poética (ZUMTHOR, 2007). É precisamente a essa energia que nos referimos para pensarmos o enfoque poético da voz em performance, sua materialidade e sua potência como manifestação do desejo, no tatear de vocalidades palhacescas.

\section{O silêncio como estratégia pedagógica}

Como nos lembra Zumthor (1997): "[...] a voz jaz no silêncio do corpo [...]. Ao falar, ressoa em sua concha esse deserto antes da ruptura, onde, em surdina, estão a vida e a paz, a morte e a loucura (ZUMTHOR, 1997, p. 12). Pensar o silêncio na relação que o mesmo exerce com a descoberta do ser palhaço ou palhaça, que começa a se "desformar" (WUO, 2016) no processo de iniciação, é um primeiro passo.

Percebemos que a presença do silêncio fez parte de quase todas as iniciações dos entrevistados e das entrevistadas como parte de seus processos iniciáticos, sobretudo para 


\section{Gilberto Icle \\ Guilherme Bruno de Lima}

aqueles do primeiro grupo (em situação pedagógica formal). E essa constatação foi, de certa forma, tanto reforçada pela identificação de desconforto com relação às primeiras tentativas de produção vocal, como também pela ênfase no saber do corpo como agente produtor das potências de afetar do palhaço, da palhaça, "suspendendo" a voz no primeiro momento.

Não obstante, pudemos averiguar ainda que 0 silêncio nessas experiências é elemento que diz respeito aos processos de subjetivação vivenciados pelos e pelas artistas e, também, a uma estratégia metodológica delineada pelos mestres desses palhaços e palhaças. Trata-se de uma metodologia de não falar.

Do ponto de vista da experiência com a voz na iniciação, somente Ésio, Jussier e José de Abreu, iniciaram-se usando sons vocais ${ }^{1}$ e até hoje são palhaços que tem a voz poética como campo de atuação e experiência. Com efeito, são palhaços que fazem uso da palavra. Por outro lado, Denis, Manuela, Sâmia, Paula e Zé Regino tiveram iniciações nas quais a experiência com a vocalidade não ocorreu e o silêncio tornou-se elemento basilar, denotado pela estratégia metodológica de seus mestres ou como no caso de Sâmia, pelo processo de aprendizagem com seu primeiro espetáculo palhacesco. Nesse sentido, tomamos como parâmetro aqui a presença da voz na iniciação

\footnotetext{
1 Sundberg, ao pesquisar a voz na fala e no canto, argumenta sobre os sons vocais, dizendo-nos que: "[...] parece correto chamar de sons vocais todos os sons produzidos pela passagem do fluxo de ar pulmonar pelas pregas vocais em vibração e pelo trato vocal, e por vezes também pela cavidade nasal" (2015, p. 19). Trata-se, portanto, de uma produção sonora efetuada pelo fator humano como sua fonte produtora e que, dependendo do objetivo com que estes sons forem produzidos, eles podem se manifestar como sons de fala ou canto (SUNDBERG, 2015).
}

e classificamos os dois grupos quanto a esse parâmetro.

No desenrolar desse emaranhado, se a voz jaz no silêncio do corpo, como o silêncio possibilita condições para que o/a iniciado/a possa fazer uso da voz poética? Quais as relações entre o silêncio e o modo pelo qual cada sujeito assimila os saberes palhacescos no corpo, que se manifesta em suas primeiras experiências? Para elucidar essas questões, traremos as vozes dos entrevistados e das entrevistadas, começando pela artista Sâmia Bittencourt.

Ela faz-nos pensar sobre sua iniciação, que não foi por um viés formal, dizendo-nos que desde o início trabalhou com o silêncio, pois num dos primeiros de seus trabalhos foi assim que descobriu "[...] uma coisa risível em [si mesma]" (BITTENCOURT, 2017, n.p.). Em 1997, ela trabalhou com Acleilton Vicente e Claudio Ivo, no espetáculo intitulado Nada, nenhum e ninguém. Segundo ela, a proposta desse espetáculo era "[...] não verbalizar, não ter voz e sim a gente falava com apitos" (BITTENCOURT, 2017, n.p.).

Sua palhaça Nada, até hoje encontra no silêncio, no não-verbal, um meio para explorar e construir sua poética. Ela diz o seguinte: "[...] não é que eu forme palhaços mudos, eu acho que isso é de cada um, é uma escolha de cada um, a palhaçaria é enorme, mas quando a gente coloca palavra, a gente mata o corpo. Então de início, eu sempre faço muito corpo e sons (BITTENCOURT, 2017, n.p.).

A artista nos remete a pensar sobre a relação voz corpo, bem como no silêncio e nas sonoridades que podem surgir na iniciação. Nesse sentido, Zumthor (2005) já havia 
estabelecido essa relação de forma peremptória, afirmando que "[...] a voz emana do corpo, mas sem corpo a voz não é nada" (ZUMTHOR, 2005, p. 89). Essa relação entre voz e corpo é evidentemente, muito complexa. Em sentido análogo, na interlocução com a fala de Sâmia, a relação palavra e corpo é também bastante abrangente. Será mesmo que a voz, que a palavra mata o corpo?

Uma "integração" entre corpo e voz, todavia, parece dimensionar a voz como um fenômeno dissociado do corpo e não se trata de integrar duas partes, pois como separar o som do conjunto corporal que o produz? (MALETTA, 2014), do corpo efetivamente? Sâmia insiste nesta relação, apontando para a importância do trabalho corporal como sustentáculo da voz. Entrementes, ela diz que descobriu na condição de professora de palhaços e palhaças "[...] que você tem que trabalhar muito o corpo, pra poder tá livre e encontrar sua voz" (BITTENCOURT, 2017, n.p.).

Por outro lado, diferentemente de Sâmia, os/as artistas Manuela, Denis, Paula e Zé Regino, iniciaram-se em contextos formais (em oficinas). Denis e Manuela em uma oficina com o Lume Teatro, em 1998, na cidade de Brasília. Paula, em 2007, com o ator João Porto Dias, numa vivência de iniciação no Nutra - Núcleo de Trabalho do Ator. Zé Regino, apesar de ter feito a oficina do Lume em Brasília, iniciou-se pouco antes, com Carlos Tamanini².

\footnotetext{
2 Ator, palhaço, professor e diretor de teatro com o qual Zé Regino teve contato na Faculdade Dulcina de Moraes, em Brasília. É considerado por Zé Regino como um de seus mestres.
}

O saber do corpo como sustentáculo da voz no contexto iniciático enfatizado por Sâmia, de certo modo, vai de encontro à própria compreensão de que a presença da palavra obstaculiza o trabalho corpóreo. Se, por um lado, o saber do corpo materializa a possibilidade de "descoberta" da voz, por outro, como a ausência da produção vocal vai de fato engendrar esta descoberta?

Manuela, por exemplo, sobre sua iniciação e a sua relação com a voz, diz que: "[...] naquele momento de nascimento do palhaço (é como se a expressão vocal) te roubasse uma energia, cinética, corporal, como se a voz te roubasse um pedaço dessa energia que, naquele momento, de repente deveria se deslocar, se concentrar para a expressão física. Então era um momento muito calado [...] eu posso dizer que o nascimento da minha palhaça foi mudo. Nem todo mundo nasce gritando ne?" (CARDOSO, 2017, n.p).

A artista, antes da iniciação, treinava o corpo tendo como suporte habilidades circenses, sem haver uma relação direta com a produção vocal. A oportunidade de iniciar-se como palhaça surgiu efetivamente na oficina do Lume, em Brasília.

O foco na pesquisa do corpo sempre guiou as pesquisas do Lume em todas suas linhas de investigação na arte de ator, inclusive no trabalho com o clown. Na época dessa oficina, os mestres pediam aos aprendizes para não falarem, conforme relatou Manuela: "[...] era pedido pra gente ficar mudo, então quando você vai falar, expressar vocalmente aquilo, tem uma dificuldade inicial. Acho que pra quem fez essa formação do Lume, eu não sei 


\section{Gilberto Icle \\ Guilherme Bruno de Lima}

se hoje é a mesma coisa, mas pra quem fez a formação tem esse impacto (CARDOSO, 2017, n.p).

Numa perspectiva semelhante à de Manuela, a artista Paula Sallas também relatou sobre sua dificuldade com a voz poética no contexto de sua iniciação, dizendo que: "foi muito complexo pra mim porque eu não trabalhava voz. Então vinha uma mistura de voz infantilizada e a minha voz normal e era um desconforto muito grande pra mim porque eu sabia que aquilo ainda não era a voz do clown, da Xicaxaxim. Aí essa foi minha primeira experiência, que foi assim desconfortável, mas por conta das primeiras investigações sobre isso mesmo" (SALLAS, 2017, n.p). A voz infantilizada a que Paula se reporta é uma voz notadamente aguda e metalizada, circunscrita a esse registro vocal bastante comum nos processos de iniciação em palhaçaria. Mas porque esse registro é comum? Pelo fato de num contexto de iniciação, os aprendentes ainda terem, muitas vezes, uma imagem "cristalizada" do que compreendem como palhaço/a, sem a necessária experiência corpórea com o universo do clownear-palhaçar (SACCHET, 2009).

Essa experiência que Paula se reporta, ocorreu em 2008, quando foi convidada para fazer uma apresentação na Funarte, em Brasília, com João Porto Dias, tido por ela como seu mestre, o qual a iniciara um ano antes. Em sua iniciação a voz não foi algo presente e, nesse sentido, a artista relatou que foi muito mais para as ações. "Eu acho que a voz pra mim é um recurso muito perigoso, por conta da minha preparação, por conta do meu histórico" (SALLAS, 2017, n.p).
A voz em performance palhacesca para essas palhaças era algo ainda muito desconfortante e o silêncio como estratégia pedagógica operou justamente no sentido de uma primeira compreensão da vocalidade poética, como modo de assimilação do processo de descoberta da palhaça, do encontro com o mundo-palhaça que aos poucos se apresentava para as artistas.

$\mathrm{Na}$ esteira dessas considerações, o artista Zé Regino, argumenta que "[...] quando eu comecei a trabalhar com palhaço eu não falava. Não me pergunta porque eu não falava [...] eu não falava. Eu fiquei [...] sei lá quantos anos, 9 anos ou mais que não falava. Fiz oficina de palhaçaria, minha primeira grande oficina com o Carlos Tamanini, eu entrei mudo e saí calado da oficina e meus números todos eram independentes da palavra. Totalmente independente, sempre (OLIVEIRA, 2017, n.p).

Zé Regino também encontrou nesse "não falar" suas primeiras formas de se relacionar com a arte palhacesca. É curioso notar que Carlos Tamanini abordava a questão da voz em suas oficinas, mas mesmo assim Zé Regino não falava. Isso demonstra que não basta a iniciação abordar a questão da voz para que o sujeito iniciante venha a produzir vocalidades.

Nesse sentido, a vocalidade poética na arte palhacesca requer um olhar atento. Trata-se de compreender a voz em sinergia com o jogo que ali se estabelece, nas centelhas de vida do corpo em ebulição no estado ridículo, cujo princípio móvel e flexível que Wuo (2016) aponta, opera nas camadas do silêncio como parte do processo de descoberta. 
Nesse sentido, podemos perceber no espectro das relações de ensino-aprendizagem e constituição de saberes palhacescos, que o silêncio como estratégia pedagógica toma forma na iniciação de modo multiperspectivado. No seio desse espectro, por outro lado, ele também pode operar de modo a confundir o iniciante no fluxo dos acontecimentos que se dão no contato com a arte palhacesca. Foi o que ocorreu com o artista Denis Camargo, que vinha de uma bagagem eminentemente teatral (assim como a maioria) e não tinha experiência como palhaço.

\section{Para ele, a iniciação}

[...] é muito crua, muito básica, principalmente pra quem não tem experiência alguma. Minha experiência anterior era de teatro e eu não tinha nenhuma compreensão de palhaço, nenhuma. Eu cheguei na oficina achando que palhaço era um personagem, que eu tinha que construir um personagem, que eu tinha que achar esse personagem cômico pra poder desenvolvê-lo. Não tinha personagem, fiquei hiper perdido. A base do material trabalhado era a exposição da minha pessoa e eu me sentia sempre mal durante o processo. No último dia eles fizeram um concurso pra eleger o melhor palhaço e na minha vida a competição sempre foi muito negada e no dia final que eu achava que ia ser o melhor dia, que a gente ia poder conversar, falaram: "vamos fazer um concurso hoje e eleger o melhor palhaço da oficina". Ali eu já fiquei puto, fiquei muito chateado. Eu não via como jogo ingênuo, eu vi as pessoas fazendo besteiras $e$ idiotices no sentido negativo e aquilo foi me irritando. Até que o Simioni me expõe diante desse grupo que tava tentando fazer o melhor pra ser eleito e pergunta: "você não quer estar aí Chupadinho?" E não podia falar e eu só balancei a cabeça negativamente né, dizendo não. (CAMARGO, 2017, n.p)

O artista sentiu dificuldades em assimilar a proposta de iniciação sem uso da voz poética, pois para ele, o fato de não poder falar, facilitou, por um lado, a metodologia para os mestres, mas por outro, dificultou seu processo de ensino-aprendizagem, de modo que ele passou a oficina sem falar guardando para si muitos questionamentos sobre esta experiência.

Em nossa entrevista ele disse, ao se referir a sua iniciação palhacesca: "não tive uma formação aonde me obrigasse a falar e entender que a voz fazia parte do corpo" (CAMARGO, 2017, n.p). É pertinente salientar que Denis passou mais de um ano processando toda essa vivência, até que numa saída de rua, no jogo travado entre ele e situações que surgiam com o público, a voz emergiu como urgência daquele momento. Retornaremos a essa experiência de Denis mais adiante.

Com efeito, no eco e na escuta atenta dessas vozes dos entrevistados e das entrevistadas tramadas na iniciação, poderia a tomada de consciência dos aspectos ridículos por parte dos e das iniciadas, encontrar no silêncio um modo de compreensão de uma nova realidade que se apresenta? Realidade que é característica mesma do estado ridículo, cuja "[...] complexidade de energias vivas e 


\section{Gilberto Icle \\ Guilherme Bruno de Lima}

pulsantes" (ICLE, 2010, p. XXII) envolve o corpo para além de sua porção física?

Como pistas que podemos lançar, consideramos que 0 fracasso seja elemento presente nessa relação como elemento-chave junto ao silêncio por compreender que o palhaço, a palhaça, são seres que fracassam, que tropeçam para tensionar o mundo, destronando-o de suas certezas e verdades enrijecidas. Como Wuo aponta, "[...] a experiência do fracasso é uma sensação que fortalece o ensino e a aprendizagem" (2016, p. 94).

É nesse movimento - físico, subjetivo, simbólico - que no processo de tomada de consciência dos aspectos ridículos, 0 fracasso e o silêncio orbitam em torno da iniciação. Nesse viés, Wuo (2009) argumenta que "[...] como uma linguagem silenciosa que comunica a lógica particular de cada pessoa, o aprendiz do curso necessita incorporar o fracasso em seu processo e reaprender, nascer de novo como uma criança para expressar-se no mundo dos clowns" (WUO, 2009, p. 60).

A autora ainda enfatiza que "[...] a compreensão da comicidade é sedimentada numa lógica desequilibrada que instiga o riso no espectador" (WUO, 2013, p. 110). Nesse sentido, no tramar dessa lógica particular de cada pessoa como potência do desequilíbrio, da inadequação e do fracasso (entre tantas outras características), que o silêncio como atributo da vocalidade pode contemplar, em maior ou menor intensidade, os iniciados e as iniciadas desta pesquisa no percurso de seus modos de fazer palhaçada.
Mas que vozes seriam essas na iniciação? Seriam somente vozes do fracasso, da inadequação? Vozes que tendem ao clichê, ao estereótipo vocal palhacesco? Vozes dissonantes, distintas daquelas vozes conhecidas como belas, "boas" de se ouvir? Para além do silêncio característico das iniciações, que outros parâmetros materiais e palhacescos podem atravessar a experiência com a vocalidade nesse território?

\section{A materialidade da voz}

[...] $A$ voz, do que eu me lembro assim, ela vinha muito através primeiro de uma respiração (Neste momento Manuela suspira), (de uma) emissão sonora. Uma voz ecoada pra dentro [...]. Sei como é que fala isso aí não, mas [...] acho que a primeira emissão, se pode dizer sonora é isso, daí o que vem pra fala é o aiaiai né? Então a voz ela vinha como proibitiva e depois ela se realiza nesse aiaiaiai e você vai aprendendo a falar (CARDOSO, 2017, n.p).

Manuela relatou que sua descoberta com a voz poética surgiu como um suspiro, no seio da expressão "aiaiai!", no respirar do aqui-agora, envolto de anseios, desejos, medos, repleto de jogo e de sensações próprias que atravessam 0 corpo na situação performática. Isso nos faz pensar em como a respiração e o suspiro são elementos que engendram esse processo.

Que relações emergem entre o silêncio, a respiração e a voz nas quais podemos pensar a voz em performance? Buscamos, portanto, no relato de Manuela, um pouso para a materialidade da voz, no entrelaçar 
de dois aspectos que consideramos relevantes em seu relato: a respiração e o suspiro.

Respirar é muito mais que uma troca gasosa e do que um componente do processo físico/fisiológico do corpo, necessário à produção vocal, de modo que a respiração está diretamente ligada à produção vocal. Bonnie Cohen, fundadora do Body-Mind Centering, em seu livro Sensing, Feeling and Action (1993), dedica uma parte à voz no que chama de Mecanismo da expressão vocal.

Ela partiu de uma provocação de seu professor na época, Erick Hawkins, o qual disse a Cohen que até que ela aprendesse a falar, ela nunca saberia como dançar. Segundo Cohen (1993),

nossa capacidade de corporificar o processo estrutural e fisiológico subjacente à respiração e à produção vocal nos dá outra maneira importante de estabelecer nossa relação com nós mesmos e com nosso ambiente. Respiração é movimento interno. Está subjacente ao movimento do corpo através do espaço externo. O movimento, de outro lado, altera nossa respiração. Respiração é organizada em padrões. Esses padrões são influenciados por estímulos emocionais. Eles também evocam respostas emocionais. Nossa primeira respiração, ao nascer, influencia o padrão de nossa respiração adulta. A respiração pode ser conscientemente conhecida. À medida que o processo de respiração é detectado, os blocos inconscientes sentidos podem ser liberados. (COHEN, 1993, p. 6, tradução nossa) ${ }^{3}$

Com efeito, a respiração, no campo das artes da cena, não é somente movimento corporal, mas também propulsora de estados na construção do tempo com o espectador (tempo da cena, tempo da ação, tempo dramático e cômico, dentre outros), estabelecendo relações bem mais complexas com o corpo. Silva nos diz:

[...] o ponto de contato entre o afeto e o corpo é a respiração. É na respiração então, que 0 duplo se configura. Assim, manejando forças afetivas e desenvolvendo uma percepção aguçada da respiração, é possível reconhecer no próprio corpo o fluxo do movimento. (apud MAFFI, 2016, p. 38)

Nesse sentido, no contexto da respiração, do corpo, o suspiro estaria ligado à expiração, como manifestação das sensações, quer seja de dor, de alívio, de prazer. Ele consiste numa expiração singular (MARTINS, 2015), tecendo uma conexão direta com a produção vocal. Ao deparar-nos com a questão da respiração e do suspiro, encontramos na proposta da

\footnotetext{
3 No original em inglês: "Our ability to embody the structural and physiological process underlying breathing and vocal production give us another important way to establish our relationship to ourselves and to our environment. Breathing is internal moviment. It underlies movement of the body through external space. Movement, in turn, alters our breathing. Breathing is organized in patterns. Thesse patterns are influenced by emotional stimuli. They also evoke emotional responses. Our first breath, at birth, influences the pattern of our adult breathing. Breathing can be consciously known. As the breathing process is sensed and felt unconscious blocks can be released". (COHEN, 1993, p. 6)
} 


\section{Gilberto Icle \\ Guilherme Bruno de Lima}

pesquisadora Kristin Linklater ${ }^{4}$, algumas reflexões. Em seu livro Freeing the natural voice (1976) ela comenta acerca do suspiro, mais especificamente do suspiro de alívio.

Suspirar e bocejar são atividades animais orgânicas que o corpo inicia quando precisa de uma carga extra de oxigênio. Bebês, cachorros e gatos bocejam abundantemente e sem embaraço muitas vezes ao dia. Eles também suspiram silenciosamente quando seus corpos necessitam de mais oxigênio. Humanos adultos vêm sendo amplamente educados distantes dessas funções naturais. Bocejar em público é tido como rude e suspirar tende a servir a um propósito emocional. Ambos podem causar algum constrangimento. Se, contudo, você agora puder experimentar os prazeres de bocejar e suspirar para o seu próprio bem, você vai revitalizar seu corpo e sua mente. A vida de seu corpo e de sua mente depende da circulação de oxigênio. Eles podem estar mal supridos dessa nutrição essencial e suas vidas sem energia em função das tensões e inibições habituais (LINKLATER, 1976, p. 50, tradução nossa) ${ }^{5}$

4 Atriz e pesquisadora escocesa que desenvolveu um método de trabalho vocal que tem como princípio liberar a voz em sua máxima expressão. Para essa liberação, todo trabalho está pautado no descondicionamento de hábitos que tem como referências pesquisas em Somática, Yoga e Tai chi.

${ }^{5}$ No original em inglês: "Sighing and yawning are organic animal activities that the body initiates when it needs an extra charge of oxygen. Babies, dogs and cats ywan copiously and whitout embarrassment many times a day. They also sigh soundlessly when their bodies need more oxygen. Adult humans have largely been educated out of these natural functions. Yawning in public is held to be rude, and sighing tends to serve na emotive purpose. Both can cause embarrasment. If, however, you can now begin to enter the pleasures of yawning and sighing for their own sake, you will, revitalize your body and your mind. The life of your body and your mind depends on the circulation of oxygen; they may well have been undersupplied in this nutrition and their life underenergized because of habitual tension and inhibition" (LINKLATER, 1976, p. 50).
A autora não fala sobre iniciação de palhaços e palhaças, no entanto, a maneira como pesquisa a voz poética e como pensa essa questão do suspiro pode nos fornecer pistas para pensarmos na vocalidade palhacesca. A partir da fala de Manuela sobre a respiração e o suspiro, por exemplo, percebemos que ambos elementos podem propiciar não só a produção de sons vocais, como também uma conexão mais profunda consigo mesmo diante do estado do ridículo. É essa conexão que nos interessa em particular pela potência que é capaz de disparar as vocalidades em território palhacesco.

O suspiro de alívio, o qual a autora se refere tem uma particular relevância pelo fato de proporcionar o exercício da conexão entre pensamento, sentimento, respiração e voz (LINKLATER, 1976), elementos fundamentais para o corpo em performance, conectando o sujeito com o momento presente. Tomamos aqui a noção de performance zumthoriana, na qual: "[...] encontraremos sempre um elemento irredutível, a ideia da presença de um corpo" (ZUMTHOR, 2007, p. 38).

É esse corpo, "[...] de um sujeito em sua plenitude psicofisiológica particular, sua maneira própria de existir no espaço e no tempo e que ouve, vê, respira, abre-se aos perfumes, ao tato das coisas" (ZUMTHOR, 2007, p. 35) que, em território palhacesco, opera também no campo material da produção vocal.

$E$ é por isso que pensar a voz em sua materialidade implica também se atentar ao fato de que a voz escapa da própria 
linguagem, que ultrapassa a própria expressão e que nesse processo tem a possibilidade de se constituir e efetivar como si própria, independentemente daquilo que se quer dizer. Conforme nos lembra Zumthor, "[...] a voz, em certos casos, se impõe a tal ponto que tende a dissolver a linguagem. Sua presença é muito intensa" (ZUMTHOR, 2005, p. 65).

Dessa possibilidade de dissolução, podemos então reter a ideia de que nem tudo na vocalidade é expressão. No que diz respeito a isso, um de nós já havia se ocupado em problematizar a voz no seio do pensamento contemporâneo (ICLE; ALCÂNTARA, 2011). Então, para se pensar a voz no território do palhaço, da palhaça, parece fundamental atentar-se a questão colocada:

[...] a expressão, tida como manifestação de um universo interior, fez parte, por longo tempo, da estruturação de um discurso verdadeiro sobre arte e sobre pensamento. Entretanto, a Filosofia, a partir, sobretudo, do que se convencionou chamar de virada linguística, tem problematizado de modo pontual a figura da expressão como elemento por intermédio do qual, termos associados como interpretação, representação, discurso, signo, voz, oralidade, têm sido problematizados e complexificados. (ICLE; ALCÂNTARA, 2011, p. 129130)

De maneira que a voz, centrada no ser, no sujeito, na consciência, como expressão de algo interno, desestabiliza-se e dá lugar a uma nova compreensão de vocalidade, propiciando novos modos de pensar que vão além dos processos de significação e chacoalham uma visão de mundo dicotômica.

Essa operação busca propor que embora a voz não prescinda totalmente da linguagem e da expressão, é na arte palhacesca que encontramos um convite bastante fértil para - extrapolar dessas dimensões, já que esse extrapolar é próprio da arte e do cômico, no seu sentido mais amplo.

Esse extrapolar se dá por diferentes maneiras de agir do palhaço, da palhaça, como sujeitos às avessas, nosenses, jocosos etc. A voz poética nesse território se espraia, se desconfigura de sua "obrigação de ser" voz, fazendo disparar toda uma materialidade de planos de vocalidade (ICLE; ALCÂNTARA, 2011), nos quais gritos, sussurros, risos, choros, cantos, palavras que ressoam impulsionadas pela loucura-transgressãocomicidade do palhaço, da palhaça, podem ampliar as possibilidades e os estratos vocais nos processos de iniciação, bem como para além deles.

Sobre a dimensão da materialidade da voz, Fischer-Lichte sublinha:

A materialidade da voz revela a materialidade da performance em sua totalidade. A voz captura a tonalidade como ela ressoa no espaço, ela enfatiza a corporalidade porque leva o corpo através da respiração; ela marca a espacialidade porque seu som flui no espaço e entra nos ouvidos dos espectadores e articula assuntos igualmente. Através de sua materialidade a voz já é uma 


\section{Gilberto Icle \\ Guilherme Bruno de Lima}

linguagem sem ter que primeiro se tornar um significante (apud JACOBS, 2011, p. 3)

Assim, na descoberta dessa lógica própria que inclui a materialidade da voz, os palhaços e palhaças foram se relacionando com a arte palhacesca por meio de suas práticas e experiências em contextos que possibilitaram, em determinado momento, que a vocalidade fosse incorporada em suas poéticas. Por outro lado, é interessante observar todo esse processo que envolve descobertas com o silêncio e com a materialidade da voz, não foi o mesmo para todos/as entrevistados/as.

Para Esio, Jussier e José de Abreu, foi um pouco diferente. Não houve essa perspectiva material, mas sim a própria fala. E para alguns desse grupo que analisamos, as experiências que fizeram emergir a vocalidade, sucederam a própria iniciação (Zé Regino e Denis, por exemplo).

Em todo caso, a voz na iniciação aponta para um mergulho em si mesmo como sujeito ridículo, que se transforma, descobrindo e incorporando novas características da voz que vão operando junto à exploração palhacesca na tessitura de saberes vocais. Nesse sentido, discutiremos acerca da voz como característica presente na iniciação dos artistas Esio, Jussier e José de Abreu. Além disso, comentaremos acerca das experiências marcantes de Denis e Zé Regino.

\section{A voz como iniciação palhacesca}

Os artistas Esio, Jussier e José de Abreu, já iniciaram trabalhando com a voz poética, descobrindo no espaço da cena, do jogo e do improviso, a vocalidade como algo característico desse processo. Por intermédio de caminhos distintos, os artistas encontraram na voz seus primeiros contatos com a arte palhacesca, característica presente até hoje em suas criações. As iniciações desses artistas chamam a atenção pelo fato de proporcionarem, em si mesmas, experiências nas quais a produção vocal está presente.

E diferentemente dos artistas que analisamos até aqui, isso propiciou, de alguma maneira, um convite à vocalidade poética, configurandose num modo de iniciação em consonância com a presença corpórea. Ao invés de reunirem no silêncio condições para em determinado momento produzirem sons vocais, esses três artistas já adentraram no mundo da palhaçaria efetuando essa produção.

Em particular, José de Abreu e Jussier, desde o início conviveram com o circo, com a lona circense. José de Abreu seguiu pelos caminhos do circo, nunca mais deixando-o. Jussier, abraçou a rua e firmou-se como artista desse universo. Ao passo que Esio, que veio de uma formação teatral, encantou-se com a possibilidade de poder fazer rir e passou por diversas experiências nas quais teve contato com o palco, com o hospital e com a rua.

Sobre sua iniciação, Esio diz:

[...] na verdade, eu sempre usei a voz em cena. Eu comecei a trabalhar o palhaço e eu lembro que um dos primeiros exercícios, ainda conhecendo o palhaço com o grupo $\mathrm{La}$ Pista $4^{6}$, eles me pediram pra cantar 0 hino nacional, equilibrando numa corda bamba, fazendo mais umas 4 ou

\footnotetext{
6 Grupo argentino que trabalha com teatro, circo e
} comicidade. 
5 coisas ao mesmo tempo, eu tinha que ter atenção numa coisa, noutra coisa, então era uma loucura, o exercício era uma loucura e já usava a voz, só que eu não pensava na voz do palhaço. (MAGALHÃES, 2017, n.p)

Esse exercício proposto pelo grupo $\mathrm{La}$ Pista 4 mostra como a vocalidade foi abordada numa simultaneidade de ações e comandos que fizeram com que Esio, no contexto da iniciação, viesse a produzir sons vocais, em especifico, através do canto. O que levou Esio a fazer essa oficina foi o fato de ter descoberto que provocava o riso num curso de teatro para iniciantes. Essa curiosidade despertou um interesse pelo riso e o encontro com o grupo La Pista 4 prepararia o terreno para o mundo da arte palhacesca.

Dessa maneira, desde o início, Esio trabalha com a voz poética, como ele próprio disse e foi encontrando na palavra seu veículo de expressão. "Eu sou um palhaço que fala muito" (MAGALHÃES, 2017, n.p.). É possível perceber isso com muita nitidez em suas criações. Até hoje a palavra é um dos elementos basilares de sua exploração poética, que tem uma função político-discursiva muito forte.

A iniciação de Ésio foi a maneira pela qual adentrou na arte palhacesca e embora tivesse, digamos, grande propensão a falar, foi a partir dessa experiência que a voz poética surgiu como demarcadora de sua iniciação.

Apesar de Esio ainda não pensar na voz de seu palhaço, o Zabobrim, ele já nasceu fazendo da experiência do falar, um modo de fazer suas palhaçadas. Todos os trabalhos de Esio tem uma estreita relação com a vocalidade e, em particular, Esio pesquisa máscara, abrangendo tanto o nariz (menor máscara do mundo) como as máscaras da Commedia Dell'art e a máscara neutra.

O nariz vermelho, considerado a menor máscara (e que porta o conhecimento clownesco), possibilita o trabalho com o cômico, pois associa ao rosto um traço diferenciado. Do ponto de vista pedagógico, o nariz implica uma modificação sobre a qual se trabalha. Para Puccetti,

[...] quando usamos a máscara passamos a descobrir certas qualidades de energia que serão usadas posteriormente no trabalho do clown. A máscara é apenas uma semente, um estado, uma sensação da qual se parte para fazer qualquer coisa. Porém, é preciso tomar cuidado para não se fixar demasiadamente estas qualidades, pois a máscara tem que ser um estado sempre vivo e mutável. (PUCCETTI, 2012, p. 87)

É justamente nesse estado sempre vivo e mutável que a voz poética opera, pois o corpo dos palhaços e das palhaças em estado performático aduz ao movimento, a um fluxo constante de trocas com o público e a uma variação de energias que sustentam a performance. Esse processo corporal, circunscreve o que percebemos em relação à voz.

José de Abreu, palhaço Pimenta, também relatou que desde o início usa a voz em 


\section{Gilberto Icle \\ Guilherme Bruno de Lima}

cena. Ele se iniciou no circo. De tanto ver os palhaços jogarem no picadeiro, acabou por memorizar as falas e os procedimentos cômicos dos artistas. Segundo ele, "[...] é dentro do picadeiro que você transforma a voz" (BRASIL, 2017, n.p).

Durante nossa entrevista, descobrimos que o circo a que José de Abreu se referia, foi o Grande Circo Rosário, o Gran Rosário Circus, circo de Antenor Pimenta, artista circense símbolo da segunda geração de circo-teatro no Brasil. Nesse período de auge do circo no Brasil, para que o circo fosse considerado bom, era preciso que 0 mesmo tivesse um bom palhaço. Máxima que ainda perdura nos dias do hoje, mas que naquela época era algo muito mais presente para os espectadores.

José de Abreu ficou encantado com tudo aquilo que via e vivia, queria se tornar palhaço e foi justamente no dia que Ubirajara Pimenta, o palhaço Tico-tico, não pôde comparecer ao circo, que José de Abreu aproveitou a oportunidade. Durante todas as noites ele ensaiava sem que ninguém percebesse, esperando 0 momento propicio para se encantar com o picadeiro. E esse dia foi o primeiro de muitos.

Sobre sua primeira experiência, ele relatou assim:

[...] a primeira vez que eu entrei de palhaço foi em 1960, foi quando... eu, eu, já era... eu já trabalhava no circo, eu já era trapezista [...] a minha voz sempre ela (esteve presente) a turma diz que eu sempre falo igual no picadeiro, mas lá no picadeiro eu puxo mais... mais criança sabe? (BRASIL, 2017, n.p)
Nessa época, havia uma distinção muito comentada pelos circenses entre o palhaço que enfocava o jogo com a palavra e o palhaço mímico, sendo este último geralmente vindo do estrangeiro. Sobre essa época que José de Abreu viveu, a pesquisadora Daniele Pimenta (2005), comenta que:

\begin{abstract}
Vem desse período de formação e desenvolvimento do circo no Brasil a distinção que circenses mais antigos fazem entre palhaço mímico e palhaço pilhérico - apoiado no humor verbal de acordo com o estilo de suas performances. Essa classificação correspondia, geralmente, à diferença entre as atuações de palhaços estrangeiros e brasileiros no mesmo picadeiro e suas diferentes formas de comunicação com 0 público. (PIMENTA, 2005, p. 20)
\end{abstract}

A piada, a pilhéria, o mundo grotesco e jocoso perpassado pela fala/palavra como manifestação do cômico, é uma das características do picadeiro brasileiro. De modo que esse contexto influenciou diretamente na iniciação de Jose de Abreu, reverberando até hoje em sua poética.

Por fim, a iniciação do palhaço Colorau, o artista Jussier Lira também se deu pelo circo e pela exploração primeira das técnicas circenses. Ele nos contou que

[...] quando surgiu a escola de circo la, aí meu irmão me chamou (e) eu fui participar da escola de circo, cheguei lá comecei a andar de perna de pau, aí gostei né, gostei, aí pronto, fui fazendo perna-de-pau, fazendo pernade-pau, aí eu fui pra monociclo ne? Comecei a andar de monociclo, aprendi foi muito la no monociclo, aí comecei a fazer as outras coisas, aí, já 
tinham falado pra mim, de perna-depau de palhaço, aí o Mateus, que é o Mateus Pinga-fogo lá de Juazeiro, ele foi quem colocou o nome de palhaço, fez a minha primeira maquiagem foi ele e colocou o nome de palhaço que antigamente era Lambreta ne? (LIRA, 2017, n.p)

Hoje Colorau trabalha na rua e domina uma roda como ninguém. Suas mãos ágeis fazem o pandeiro ser um grande aliado na busca pela comicidade. Seu improviso com gags construídas junto a seu partner, entremeadas pela embolada, é como o lançar de uma carta de baralho numa mesa de jogo: preciso.

Jussier começou sua estrada em Juazeiro do Norte, no Ceará, sua cidade natal, numa escola de circo chamada Barraca da União, muito incentivado pelo seu irmão que já era palhaço, o palhaço Sucata. $O$ ano era de 1990. Perna-de-pau, monociclo, dentre outras técnicas circenses já provocaram interesse no artista, que passou a treinar essas técnicas ao ingressar no circo.

Um dia, fazendo uma caminhada de pernade-pau por Juazeiro, de palhaço, encontrou com o Mateus Pinga Fogo. O Mateus batizou Jussier de Lambreta e fez a sua primeira maquiagem. Simbolicamente, esse foi seu início na arte palhacesca e Jussier já usava a voz poética em cena, nas improvisações que fazia no circo, porém segundo ele, foi a partir de então que começou a fazer palhaço de fato.

$\mathrm{Na}$ esteira desse processo, Jussier foi para Fortaleza e lá assistiu um palhaço que the chamou muito a atenção. Ele relatou que não lembra o nome do palhaço, mas the impressionara como o artista performava a voz em cena: seu timbre, seu jeito de falar, seu jogo com o público por intermédio da voz. Conforme Colorau relatou, essa experiência propiciou para ele um novo olhar sobre a voz poética. Ele diz:

[...] fui assistir um show no circo e vi um paiaço muito antigo, eu nem me lembro mais o nome dele. O circo dele, ele falava sem microfone sem nada e a voz dele estrondava dentro do circo ne? Aí eu gostei e vi, eu digo assim, rapaz, eu vou usar esse mesmo estilo aí e usar essa voz também, aí comecei a treinar a voz ne, e foi dando certo e foi pegando [...] Treinando e fazeno, trabalhano e fazeno ne... aí fui aperfeiçoando mais a voz do Colorau, aí já aprendi a voz ne? Aí já mudou ne... aí eu disse rapaz... já que eu mudei a voz do paiaço, então eu vou ter que mudar o nome do paiaço também ne? Aí pronto, aí foi que surgiu esse negócio, esse paiaço Colorau. (LIRA, 2017, n.p)

A relevância da voz para a composição poética do artista Jussier, que ainda estava no começo de sua jornada na arte palhacesca foi de tal maneira, que ele mudou o nome de seu palhaço passando a se identificar com um tipo de produção vocal que ele tinha visto a partir dessa experiência como espectador.

Chamou-lhe a atenção a performance vocal do palhaço a quem assistiu e desde então, Lambreta não era mais Lambreta e eis que nasce Colorau, um nome que vinha de suas memórias de infância quando ele era apelidado de "Corante" pelos colegas da escola e do bairro. 


\section{Gilberto Icle \\ Guilherme Bruno de Lima}

Por fim, no grupo dos oito entrevistados, duas falas nos chamaram a atenção. Nelas, curiosamente, os dois entrevistados usaram a mesma expressão para se referirem a primeira experiência com a vocalidade: um marco, segundo eles. Os entrevistados foram Denis Camargo e Zé Regino. Denis, por exemplo, relatou-nos que

[...] a primeira vez mesmo que a voz veio, foi numa saída de palhaço num projeto do Celeiro das Antas, Encantadores de Borboletas, que era promovido pelo Zé Regino. Foi em 2000, no Gama. Eu não queria falar, eu tinha saído da oficina do Lume e palhaço meio que não falava na época. Achava que palhaço não falava... aquelas coisas. Aí o filho de um dos palhaços ficou me pentelhando, desde o processo de trocar de roupa, sair lá da sede e chegar a rodoviária do Gama. Ele não me soltava e essa coisa de me segurar sempre foi uma coisa me agoniou demais. Eu cheguei na rodoviária dei um surto e comecei a gritar e girar pra ver se o menino me soltava. Foi um ato hiper violento, mas foi hiper libertador porque eu gritei e depois saí correndo igual um maluco nessa rodoviária e parei diante de uma barbearia e disparei a falar, foi um processo assim como se tivesse botando pra fora todo aquele tempo de palhaço que não tinha falado nada. Nunca esqueço a imagem, que pra mim é marcante. Mas por outro lado eu não entendia o processo da fala, só falava, falava, falava e às vezes não respirava direito. (CAMARGO, 2017, n.p)

Experiência semelhante se deu com 0 artista Zé Regino, porém, 9 anos após a sua iniciação. Apesar dessa experiência não se situar cronologicamente no início de sua trajetória, ela possibilitou novos horizontes e o palhaço de Zé Regino, antes chamado Zico, a partir de então se chamaria Zambelê. Como Zico não falava, nem produzia sons de nenhuma maneira. Por volta dos anos 1990, o artista saiu de Brasília na companhia dos artistas Chico Simões e Roseane para fazer apresentações itinerantes numa pesquisa sobre o Mateus, palhaço popular do reisado.

Nessa viagem, numa parada no estado de Minas Gerais, Zé Regino contou sobre uma experiência que apontaria uma nova etapa de sua trajetória. Ele teve um insight muito provocador que o fez reconectar-se com sua dimensão mineira, sua cultura de origem. Sobre essa experiência ele diz:

De repente eu vejo uma senhorinha, bem velhinha, atravessando a rua, tava no outro canto da praça, quase no extremo no que eu estava. Eu comecei a olhar essa figura e me perdi no pensamento, olhando praquela senhora, quando de repente eu levei um susto, ela estava do meu lado. Ela passou, parou aqui do meu lado, aí eu olhei e ela parou assim, olhou pra mim e falou desse jeito: "Até parece que veio de tão longe só pra ficar me vendo". Aquele jeitinho mineirinho assim, sabe? E aí, voltou pra onde ela tava. $E$ aquilo me deu um insight, me deu um trem, assim, PAF (OLIVEIRA, 2017, entrevista)

Ao escutar a prosódia mineirinha dessa senhora, na praça da cidade no interior de Minas, as memórias mineiras de Zé Regino vieram à tona de tal modo que ele passou a tagarelar ininterruptamente. Ao retornar da praça para o teatro onde iria se apresentar 
logo mais, Zé Regino surpreendeu seus colegas de trabalho pela tagarelice.

Ele conta que isso fez com que percebesse seu palhaço de outra maneira e a partir de então, passados nove anos trabalhando sem a voz, sem a palavra, Zé Regino se reinventa pela vocalidade. Assim, ele relatou:

[...] Eu entrei numa de dar vazão pra esse meu universo mineiro, pra deixar essas minhas origens, essas minhas fontes, essas minhas lembranças, virem à tona, mesmo. Foi uma coisa tão incrível que eu comecei a tagarelar com o meu palhaço com uma liberdade, eu comecei a improvisar pela primeira vez na minha vida, mas de um jeito, que quando a gente chegou em Brasília pra fazer uma série de apresentações, o Chico e a Rose falaram: 'Cara não dá mais, você não é o Zé Mateus, acabou! Zé Mateus não tem mais a ver com isso". E aí eles me batizaram de Zambelê, que é o meu palhaço atual. (OLIVEIRA, 2017, entrevista)

A experiência de Zé Regino propiciou um reencontro com seu imaginário mineiro, disparado pelo acontecimento narrado no qual esse pertencimento a cultura mineira foi acionado, tornando-se peça-chave na composição de uma outra figura, outra vida, com outra silhueta: Zambelê. E, ao mesmo tempo, acontece um novo ritual de iniciação/passagem na arte da palhaçaria. $O$ artista recria a maneira de fazer seu palhaço, inventa novas relações com essa arte e com a vocalidade em seu sopro criador (ZUMTHOR, 1997).
Podemos perceber o quanto a experiência com a voz tem a força e a potência de afetar e constituir-se como marca fundante das trajetórias desses artistas em particular (Esio, Jussier, Colorau, Denis e Zé Regino), sejam elas circunscritas à iniciação propriamente dita ou não, fazendo-nos pensar sobre os modos como se tecem poéticas vocais palhacescas, em sua trama de saberes e práticas.

Por isso a vocalidade pode ser entendida como um marco (ou ainda como marcos), disparada por acontecimentos singulares para cada um/uma e $(\mathrm{m})$ seus percursos de vida e arte palhacesca, nos quais, "[...] através de corpos permeáveis de ideias flexíveis, clownspalhaços podem atravessar, levados pelo seu jogo, diferentes poéticas" (SACCHET, 2009, p. 101).

São essas poéticas, bem como seus saberes e práticas que destilam ao longo do tempo experiências diversas e complexas, perpassando do triunfo ao fracasso, do sublime ao grotesco, modos de palhaçar, de inventar-se a si em território ridículo, num processo em movimento constante, por toda a vida, considerando sempre a relação (consigo, com o outro, com o mundo) como elemento vital da vocalização de afetos (ZUMTHOR, 1997). É a passagem para o vocalizar dos afetos que consideramos como marcos das vocalidades palhacescas.

\section{No tatear de vocalidades palhacescas: tramas de saberes práticos e poéticos da voz}

Neste texto, propomos refletir num recorte delimitado sobre as iniciações dos palhaços e 


\section{Gilberto Icle \\ Guilherme Bruno de Lima}

das palhaças estudados e em suas experiências oriundas do circo e do teatro. Trata-se aqui de perguntar: como a voz poética permeia os processos de iniciação desses sujeitos na arte palhacesca? Como se constitui a poética vocal de um palhaço, uma palhaça? Procuramos vislumbrar a noção de iniciação como aspecto central para daí lançarmos um enfoque sobre a voz em performance, tratando, portanto, de analisar seus elementos materiais e simbólicos na constituição dos sujeitos iniciantes como palhaços e palhaças.

Uma possível noção de vocalidade palhacesca pode agora ser lançada: ela faz, em maior ou menor intensidade, borrar a linguagem $e$ dissolver os sentidos rígidos dos discursos e das normas, tal como o faz a arte do/a palhaço/a. Tramada à iniciação, essa vocalidade engendra modos de pensar a voz como elemento poético de intensa potência, capaz de dar vazão a sonoridades, muitas vezes silenciadas.

Mas não se trata somente de fazer ouvir vozes que estão, possivelmente, caladas. Trata-se de compreender os usos da voz poética, no rastro da proposição zumthoriana, para potencializar a arte palhacesca no tocante à voz no sentido de operar em possíveis movimentos desta potência. Destacamos três deles: 1) a compreensão da voz poética em sem campo material e sua gama de possibilidades como fonte produtora de sons e discursos; 2) a noção de provocar um olhar multiperspectivado sobre a voz como recurso cênico-palhacesco no seio do jogo pedagógico para fazer desestabilizar um pensamento de que palhaço/palhaça sempre se inicia sem relação com a produção vocal; e 3) a ideia de desencadear estratégias de intervenção estéticopoéticas capazes de problematizar os estereótipos vocais presentes na arte palhacesca, instigando condutas de criação e de saberes que dissolvam esses estereótipos.

Esses movimentos foram possíveis de serem pensados no jogo entre o saber empírico dos e das entrevistadas e o universo de conceitos aqui travados. Pensá-los na iniciação é uma estratégia pautada no entendimento de que a mesma é vital para o percurso no qual a voz possa vir a constituir-se numa poderosa aliada da performance artística de um palhaço ou palhaça.

Léo Bassi, não nos fala sobre iniciação, porém, como cômico-palhaço-bufão de intensa atuação, que encontra na voz rico manancial poético e político no seu modo performático de provocar a crítica e o riso, tem uma percepção que nos instiga, pois diz que "[...] na história do circo, os palhaços, tinham um grandíssimo comentário político. [...] o palhaço era a alma e o espírito do circo; era ele que podia falar. [...] era a voz do pobre, era a alma, o espírito do povo" (apud SACCHET, 2009, p. 27-28).

Compreendemos que a genealogia da tipologia cômica do/a palhaço/a não se restringe ao circo, sobretudo na contemporaneidade na qual a atuação desses artistas em outros espaços, como o teatro, o hospital, a rua etc., tem se intensificado e se difundindo. Porém, de que maneira tem se dado os usos e saberes da voz poética? Como a iniciação pode potencializar esses usos/saberes não necessariamente para fazer palhaços e palhaças "falarem", "produzirem sons", tampouco para seguirem poéticas como a de Leo Bassi, mas sim para mergulharem em investimentos peculiares de energias que as vocalidades disparam?

Assim, atrelados aos movimentos que traçamos, é preciso lembrar que a voz poética em território

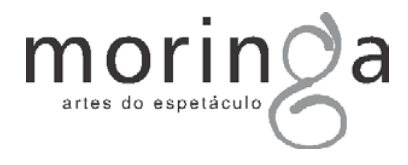


palhacesco é um fenômeno que precisa ser (re)pensado tanto na iniciação como para além dela, para aproximarmo-nos de suas potências. Trata-se de reconhecer nossos próprios modos de entender a arte do/a palhaço/a, fissurando-a para tatearmos, na trama de práticas, poéticas e saberes, vocalidades palhacescas: plurais, nômades, sublimes, grotescas, jocosas, transgressoras, desgarradas, desarrazoadas, questionadoras, poéticas enfim.

Recebido em: 15/01/2018

Aceito em: 06/03/2018

\section{Referências Bibliográficas}

BRASIL, José de Abreu. Entrevista VI. Entrevistador: Guilherme Bruno de Lima. Fortaleza, 6 de junho de 2017. Não publicada.

BITTENCOURT, Samia. Entrevista VIII. Entrevistador: Guilherme Bruno de Lima. Fortaleza, 6 de junho de 2017. Não publicada.

BURNIER, Luís Otávio. A arte de ator: da técnica à representação. Campinas: Editora Unicamp, 2009.

CARDOSO, Manuela Castelo Branco de Oliveira. Entrevista IV. Entrevistador: Guilherme Bruno de Lima. Brasília, 20 de abril de 2017. Não publicada.

COHEN, Bonnie Bainbridge. Sensing, Feeling and Action: the experiential anatomy of bodymind centering. Massachusetts: Contact Editions, 1993.

CAMARGO, Denis. Entrevista III. Entrevistador: Guilherme Bruno de Lima. Brasília, 18 de abril de 2017. Não publicada.

ICLE, Gilberto. O Ator como Xamã: configurações da consciência no sujeito extracotidiano. São Paulo: Perspectiva, 2010.
ICLE, Gilberto; ALCANTARA, Celina Nunes. Teatro, palavra, performance: pensar a voz para além da expressão. Repertório, Salvador, ํㅜ 17, p.129-135, jul-set 2011. Disponível em: $<$ https://portalseer.ufba.br/index.php/revteatro/artic le/view/5733/4275>. Acesso em: 30 mai. 2017.

JACOBS, Daiane Dordete. Voz em Performance - reflexões sobre a performatividade da voz em trabalhos de Meredith Monk, Laurie Anderson e Vito Acconci. Porto Alegre: VI Reunião Cientifica da Abrace, 2011. Disponível em: <http://www.portalabrace.org/vireuniao/processos/ JACOBS,\%20Daiane\%20Dordete\%20Steckert.p df>. Acesso em: 10 dez. 2016.

LIGNELLI, César. Sons e(m) Cena: parâmetros do som. Brasília: Editora Dulcina, 2014.

LINKLATER, Kristin. Freeing the Natural Voice. California: Drama Publishers, 1976.

LIRA, Jussier. Entrevista VII. Entrevistador: Guilherme Bruno de Lima. Fortaleza, 6 de junho de 2017. Não publicada.

MAFFI, Kátia Milene dos Santos. Técnica Klaus Vianna: apontamentos sobre a produção cinético-sonora. 2016. Dissertação (Mestrado em Artes Cênicas) - Brasília: Universidade de Brasília, 2016. Disponível em: $<$ http://repositorio.unb.br/bitstream/10482/21271/1 /2016_K\%C3\%A1tiaMilenedosSantosMaffi.pdf>. Acesso em: 09 de janeiro de 2018.

MAGALHÃES, Esio. Entrevista I. Entrevistador: Guilherme Bruno de Lima. Campinas, 01 de março de 2017. Não publicada.

MALETTA, Ernani de Castro. A dimensão espacial e dionisíaca da voz com base nas propostas de Francesca Della Monica: resgatando liberdade expressiva e identidade vocal. Revista Urdimento, Florianópolis, 


\section{Gilberto Icle \\ Guilherme Bruno de Lima}

UDESC, v.1, n. 22, p. 39-52, 2014. Disponível em:

http://revistas.udesc.br/index.php/urdimento/article /viewFile/1414573101222014039/3212>. Acesso em 2 novembro de 2017.

MARTINS, José Batista Dal Farra. Sete postulados para uma pedagogia da vocalidade poética. Revista Cena, Porto Alegre: UFRGS, ํㅜ 17, 2015. Disponível em: http:/seer.ufrgs.br/index.php/cena/article/view/552 37. Acesso em: 10 jul. 2017.

PIMENTA, Daniele. Antenor Pimenta: circo e poesia: a vida e o autor de - E o céu uniu dois corações. São Paulo: Imprensa Oficial do Estado de São Paulo: Cultura, Fundação Padre Anchieta, 2005.

PUCCETTI, Ricardo. O Clown através da máscara: uma descrição metodológica. ILINX Revista do Lume, Campinas: UNICAMP, v. 1, no 1, 2012. Disponível em: http://www.cocen.unicamp.br/revistadigital/index.p hp/lume/article/view/194. Acesso em: 20 fev. 2017.

OLIVEIRA, Jose Regino. Entrevista V. Entrevistador: Guilherme Bruno de Lima. Brasília, 26 de abril de 2017. Não publicada.

SACCHET, Patrícia de Oliveira Freitas. Da discussão "clown ou palhaço" às permeablidades de clownear-palhaçar. 2009. Dissertação (Mestrado em Artes Cênicas), Porto Alegre: Universidade Federal do Rio Grande do Sul, 2009. Disponível em: < http:/www.lume.ufrgs.br/handle/10183/17730>.

Acesso em: 12 de novembro de 2017.

SALLAS, Paula Renata da Rocha e. Entrevista II. Entrevistador: Guilherme Bruno de Lima. Brasília, 14 de abril de 2017. Não publicada.
SUNDBERG, Johan. Ciência da voz: fatos sobre a voz na fala e no canto. Trad. Gláucia Laís Salomão. São Paulo: Edusp, 2015.

WUO, Ana Elvira. A linguagem secreta do clown. Revista Integração, São Paulo-SP, ano XV, no 56, 2009. Disponível em: $<$ http://www.teatronacomunidade.com.br/wpcontent/uploads/2014/02/A-linguagem-secretado-clown.pdf. $>$. Acesso em:10 mai. 2017.

WUO, Ana Elvira. Comicidade: do "corpar" clownesco como princípio móvel, flexível, risível e espontâneo na (des) formação do ator. Revista OuvirOUver, Uberlândia-MG, v. 9, n. 1, p. 108116, 2013. Disponível em: $<$ http:/www.seer.ufu.br/index.php/ouvirouver/articl e/viewFile/28129/15507>. Acesso em: 03 de outubro de 2017.

WUO, Ana Elvira. Clown: "desforma", rito de iniciação e passagem. 2016. Tese (Doutorado em Artes da Cena) - Campinas: Universidade Estadual de Campinas, 2016. Disponível em: $<$ http://taurus.unicamp.br/bitstream/REPOSIP/321 826/1Muo_AnaElvira_D.pdf>. Acesso em: 5 de maio, 2017.

ZUMTHOR, Paul. A letra e a Voz: a "literatura medieval". trad. Amálio Pinheiro, Jerusa Pires Ferreira. São Paulo: Companhia das Letras, 1993.

ZUMTHOR, Paul. Introdução à Poesia Oral. São Paulo: Hucitec, 1997.

ZUMTHOR, Paul. Escritura e Nomadismo. Cotia-Sp: Ateliê editorial, 2005.

ZUMTHOR, Paul. Performance, Recepção e Leitura. São Paulo: Cosac Naify, 2007. 